\title{
Interromper o instante, interrogar o agora: poesia, política e pensamento em Alberto Pucheu
}

Gustavo Silveira Ribeiro ${ }^{1}$

para Marina e Laura

O que significa pensar poeticamente o presente? Entre tantas outras, essa parece ser a pergunta fundamental que atravessa, secreta e subterrânea, o livro de poemas Mais cotidiano que o cotidiano (Azougue, 2013), de Alberto Pucheu. Poesia híbrida, habitando, às vezes harmônica, às vezes dramaticamente, uma espécie de fronteira, ela se dilacera o tempo todo entre o verso e a prosa, a voz e a letra, o autobiográfico e o impessoal, a notação lírica e o dado reflexivo do ensaio, a literatura e a filosofia, enfim. De modo mais intenso do que boa parte de sua geração (Eucanaã Ferraz, Cláudia Roquette-Pinto, Ricardo Aleixo, por exemplo), Pucheu procura investigar os sentidos do contemporâneo, fazendo de sua poesia, em mais de um momento, palco privilegiado de um debate complexo (poetológico e também ético), sobre as formas, as contradições, as catástrofes do seu tempo (que é igualmente nosso) e a maneira de representá-las, isto é, não apenas de passá-las ao papel, mas, sobretudo, de as enfrentar e revirar, fazendo da mimese campo de produção e dúvida, no qual a repetição e o reconhecimento não são os elementos principais.

Desde o título do volume, Mais cotidiano que o cotidiano, é nítida a atenção ambígua que o poeta confere ao tempo, à sua relação singular com o tempo (ao seu cotidiano), mas também com a época em que lhe foi dado viver e escrever. Ao escavar os significados que se escondem sob as ações do cotidiano (sob o próprio sintagma e suas variações), a poesia de Pucheu traz à tona diferentes camadas e direções que o tempo pode assumir, revelando que aquilo que nos move no correr dos dias são possibilidades, são temporalidades distintas que se combinam e delineiam o simples existir:

${ }^{1}$ Doutor em estudos literários e professor adjunto da Universidade Federal de Minas Gerais (UFMG), Belo Horizonte, MG, Brasil. E-mail: gutosr1@ @otmail.com 
$[\ldots]$

Não,

não são os grandes motores que nos movem

cotidianamente, mas aqueles

que trabalham em baixa rotação,

que quase não se deixam perceber

senão quando subitamente engasgam

e, de repente, esgarçam o tecido

do tempo, que aparece em seu limite,

em sua negação, em seu mais fora

do presente, do passado e do futuro,

fraturado, deixando aparecer,

na fratura, um tempo outro, um contratempo,

um antitempo, um antetempo, um outro

lado do que chamamos como tempo [...] (Pucheu, 2013, p. 29)

No coração do cotidiano, há uma fratura, uma cisão que indica a possibilidade de "um tempo outro", no qual, claro está, outros valores e vivências podem esboçar-se. Nesse sentido, e em primeiro lugar, trata-se de notar como se afirma, no texto, um modo de estranhamento ao presente: a expressão que serve de base ao título indica a distância que o livro mantém em relação ao tempo vazio do hábito e dos dias circulares, das grandes narrativas e seus sentidos prontos e transbordantes - assim como também da chamada poesia do cotidiano, de longa memória na lírica moderna e contemporânea (Willian Carlos Willians, Wislawa Szymborska, Adília Lopes, por exemplo) e que, no Brasil, aproxima nomes como Manuel Bandeira, José Paulo Paes e Adélia Prado. O suplemento aqui (como também para Jacques Derrida) indica diferença, curiosamente: em vez de se render mais diretamente aos pequenos gestos e fendas do dia a dia, tratando de representá-los e de desentranhar deles a matéria do poema, o livro prefere desfazer a trama do cotidiano individual, de corte familiar e narcísico, a fim de expor aquilo que há de comum, de coletivo e impessoal, de apropriável e anônimo, na vida e na história do presente. Mais cotidiana que o cotidiano, nesse sentido, é a exploração de uma fissura no tempo, uma pequena abertura que possibilita a contemplação de zonas inesperadas no fluxo de acontecimentos que, na sua sucessão contínua e tantas vezes invisível, chamamos tempo presente. O agora, para Pucheu, são os rasgos no tecido homogêneo do tempo, interrupções que permitem imaginar, 
ainda que na brevidade de um instante, aquilo que o mundo guarda como potência e força de criação. Mesmo quando se aproxima de uma certa figuração da intimidade - e há toda uma seção do livro ("O livro de hoje do amor") dedicada ao encontro erótico e à experiência amorosa, nos quais muito do espaço privado está exposto e devassado - a tônica é sempre a da desfamiliarização, do desencontro com a experiência codificada e sempre fácil de reconhecer. A representação do sexo e do convívio amoroso terá sempre para o poeta, ao menos nesse livro específico, a marca de um desconhecimento, seja pelo aproveitamento muito habilidoso que faz dos textos e histórias de outros (amigos, escritores, estranhos), seja pelo que há de misterioso e imprevisível na rotina apresentada, na mulher a quem muitas vezes o eu-lírico se endereça em cada poema.

Num segundo momento, no entanto, é possível notar no livro um interesse profundo, quase obsessivo, com o mundo contemporâneo, seus sons, seus discursos, seus riscos e potencialidades. Quase toda a série dos "arranjos", sobre as quais voltaremos a falar com cuidado mais adiante, é índice disso: nela está cifrada, de modo ao mesmo tempo muito direto e muitíssimo elaborado, uma espécie de instantâneo sonoro (e moral) de nossa época, no qual se guardam as muitas violências e algumas belezas que cercam a vida que nos foi dado viver e observar. Nos textos "Arranjo para tornar o mundo cada dia pior e mais violento (antivoz)" [partes I e II] e "Arranjo para tornar o mundo cada dia menos violento (pós-voz)", por exemplo, pode-se, respectivamente, ouvir a voz fria e terrível de Anders Breivik, o terrorista que detonou explosivos e assassinou a tiros 77 pessoas (a maioria jovens) na Noruega, em 2011:

quero deixar bem claro que eu sou contra as guerras ou quaisquer que sejam os atos de violência sem motivo justo, e também quero deixar bem claro que eu não sou o responsável por todas as mortes que ocorrerão, embora meus dedos serão responsáveis por puxar o gatilho. [...] os conservadores precisarão tomar o poder político e militar dentro dos próximos 70 anos, senão a única alternativa será a continuidade do modelo de bastardização, muito próximo ao do Brasil, onde tem vigorado a miscigenação. essas orientações se mostraram catastróficas (Pucheu, 2013, p. 23-24).

Vê-se também os nomes de parte de suas vítimas, mesclados aos nomes dos mortos em outro atentado, ocorrido no Brasil, numa escola do bairro do Realengo, periferia do Rio de Janeiro, no mesmo ano. Dispostos em 
sequência livre, sem nenhum outro qualificativo ou organização, os nomes formam um recitativo grave, de tonalidade fúnebre e algo religiosa, nos quais as vítimas quase desconhecidas da violência incompreensível se aproximam e se tocam, construindo a estranha semelhança do absurdo e a solidariedade que a dor pode proporcionar:

Ana Carolina Pacheco da Silva, Bianca Rocha Tavares, Géssica Guedes Pereira, Karar Mustafa Qasim, Andreas Edvardsen, Ronja Sottar Johansen, Emil Okkenhaug, Asta Sofie Helland Dahl, Monica Iselin Didriksen, Rune Havdal, Tore Eikeland, Espen Jorgensen, Karin Elena Holst, Aleksander Aas Eriksen, Victoria Stenberg, Ruth Benedicte Vatndal Nilsen, Isabel Victoria Green Sogn, Ida Beathe Rogne, Elisabeth Tronnes Lie, Monica Elisabeth Bosei, Igor Moraes, Havard Vederhus, Carina Borgund, Ingrid Berg Heggelund, Tarald Kuven Mjelde, Porntip Ardam, Andrine Bakkene Espeland, Torjus Jakobsen Blattmann, Jamil Rafal Mohamad Jamil, Tina Sukuvara, Karine Chagas de Oliveira, Larissa dos Santos Atanásio, Fredrik Lund Schjetne [...] (Pucheu, 2013, p. 27).

Essa atenção expectante àquilo que, no presente, circula como linguagem comum, ora violenta e brutal, ora inocente e melancólica, vem acrescentar uma outra dimensão à relação propriamente política que o poeta mantém com sua época. Se a recusa do cotidiano alienado levava a poesia até os motores "de baixa rotação" e às fissuras da superfície porosa do mundo contemporâneo, revelando o que há nelas de maquinismo e sobredeterminação, a abertura e interesse em relação aos acontecimentos da cena contemporânea, muito notáveis em Mais cotidiano que o cotidiano, dão ao livro um sentido de memória viva do seu próprio tempo, na qual vão se depositando as experiências mesquinhas, os xingamentos, as imagens insuportáveis, as vozes esquecidas ou desimportantes que o constituem e distinguem. Aquilo que é, no livro, experimentação de novas formas poéticas, de caminhos diversos para o impasse formal que muitas vezes se impõe, é também chave para a reflexão de natureza social que ali tem lugar, num modo de aproximação tensa entre ética e estética, que faz com que a busca por novos modos de expressão seja igualmente a chave para a elaboração de novas maneiras de interrogar o agora, novos instrumentos com que sondar a si e ao outro.

Nesse sentido, uma das estratégias desenvolvidas pelo autor pode ser descrita como uma muito particular teoria da despossessão. Tanto 
no que se refere à construção dos seus poemas, como artefatos de linguagem, quanto à dança das ideias que eles propõem, está-se diante, no livro em tela, de um processo de renúncia à posse das palavras, ao rigor da identidade e da assinatura, ao conforto do pertencimento. Muitos são os textos nos quais figuram bárbaros desterrados, migrantes em viagem, sujeitos (o próprio poeta, entre tantos outros) que existem, preferem existir antes de "qualquer direito,/de qualquer convenção, do livre arbítrio,/do estado civil, antes do tamanho dos ossos,/do formato da orelha, das impressões digitais/dos dedos, das extensões do rosto, da fotografia" (Pucheu, 2013, p. 34), antes de qualquer coisa que os limite e condicione, aprisionando-os nos compartimentos estreitos da identidade servil e do poder, especialmente o biopoder - controle dos corpos e do que neles é centelha de vida.

Assim como os sujeitos dessubjetivam-se, reconhecendo-se uns nos outros como matéria comum, comunidade que vem, comunidade não gregária que partilha atributos e não pode ser de todo assujeitada (conforme está posto no belíssimo "Poema para ser lido na posse do presidente", talvez o eixo em torno do qual o livro gira), a própria linguagem com que se erguem os poemas encontra-se, ela também, dessubjetivada e impessoal, feita de retalhos de outras vozes e outros discursos. Poesia em língua alheia, poder-se-ia dizer, na medida em que se alimenta e informa de diferentes assinaturas e falas, num gesto de busca e acolhimento que guarda muito do sentido ético do livro. Próximo e distante, a um só tempo, de outros escritores brasileiros que têm se utilizado de procedimento similar (de modo especial Angélica Freitas em Um útero é do tamanho de um punho e Verônica Stigger em Delírio de Damasco), Pucheu encontra nos seus arranjos um modo de celebrar e exorcizar as vozes invasivas do presente, vozes que se impõem aos ouvidos do escritor que parece disposto a suportá-las, trazendo-as para dentro do texto poético de modo a mostrar que elas podem, ao mesmo tempo, alargar a experiência criativa - fazendo-a falar por meio de uma voz coletiva e imprópria, capaz de descentrar poeta e poema - e resistir a essa mesma experiência, emperrando-a em alguns momentos, apontando para os limites da linguagem e da razão.

Leitor de filosofia antiga e contemporânea, de Platão e Agamben, ensaísta e crítico literário, Pucheu - autor de, entre outros, apoesia contemporânea e Kafka poeta, ambos de 2015 - parece ter tomado as palavras de Jean-Luc Nancy (em Résistance de la poésie) como mote e 
senha de seu livro, voltando-a para o que há de metatextual e de político nele: "a poesia não coincide com si, pode estar onde a própria poesia é ausente. Essa não-coincidência, essa impropriedade essencial é o que faz da poesia, poesia" (Nancy, 2005, p. 11). A impropriedade essencial da poesia, a não coincidência consigo, escusado é repetir, diz respeito também à condição do poeta e do homem comum, sempre em desacordo essencial e libertador com o que há em si de identidade e repetição não diferenciada. Essa impropriedade diz algo também à ambiguidade da vida nua que nos habita e constitui como corpos - vida dessacralizada e de tudo despojada, do mesmo modo que é também vida pura potência, infinitamente desdobrável diante de si. Ou, conforme as palavras do poeta:

[...] São corpos matáveis, como

ao fim de uma partida de futebol, como durante um assalto, como na fila de um hospital, ou por bala perdida ou certeira polícia e dos traficantes, como por acidentes, pelas drogas, pela fome...

São corpos gloriosos, como durante uma partida de futebol, como durante uma semana de carnaval, como em um show de rock, em uma mesa de bar com amigos, em um mergulho noturno ou diurno no mar, como quando fazem amor ou quando, mesmo sem o fazerem, se amam por toda a vida ou por apenas alguns instantes (Pucheu, 2013, p. 34-35).

Outro desenvolvimento ainda, por fim, pode ser percebido nessa interseção entre as questões que aqui estão em jogo. O tópico da poesia em língua alheia, que aproveita as vozes e ruídos do mundo circundante para transformá-los em sentido e obra, é lançado a outro patamar por dois outros poemas: "Iaque" e "Perfil parcial de um procedimento, escrito por Caio Meira". Em ambos, o registro é francamente autobiográfico, mas a distância que se quer manter em relação ao eu e à verdade do sujeito não poderia ser maior. No primeiro, o poeta deseja a incompreensão, a despossessão total como condição primeira para falar de si, discurso que só pode se dar num idioma estranho, não conhecido e impronunciável. $\mathrm{O}$ símile buscado guarda a radicalidade da proposta: o poeta gostaria de ver a 
si mesmo (e traduzir-se em linguagem, claro está) com os olhos, a sensação de um animal desconhecido a "atravessar um despenhadeiro do Himalaia" (Pucheu, 2013, p. 49), pura presença que desconhece a si, metafisicamente falando, mas que tem segurança na travessia arriscada que faz. No segundo poema, por sua vez, as anotações - ficcionais ou não - do poeta Caio Meira sobre Pucheu indicam duplamente que a escrita em Mais cotidiano que o cotidiano se faz como estranhamento e se alimenta de palavras alheias, a modo de impostura: não só o poema é escrito por outrem, como tem como matéria uma cena em que Alberto Pucheu, jovem e ainda tateando a linguagem em busca da sua própria dicção, anota palavras soltas, lidas e ouvidas ao acaso, nos encontros e esbarrões do trem de passageiros da Central do Brasil, numa cena que irá funcionar como uma espécie improvável de poética, a narrativa das origens dos arranjos - cuja estrutura musical, intuída em seu nome, revela-se de pronto; é como se a abstração geográfica em que habitamos, nos diz Meira/Pucheu, finalmente pudesse ser ouvida: "A cidade passava a se dizer [- a cantar a si mesma? -] pela voz de seus próprios cidadãos" (Pucheu, 2013, p. 53).

A reversão que esses textos colocam, vista em perspectiva numa tradição poética como a brasileira, na qual a poesia confessional, atada fortemente à experiência irredutível do indivíduo, é dominante, assinala verdadeira conquista, na medida em que, mais uma vez, parece unir as duas pontas do projeto que se desenha no livro: ao desenvolver novas possibilidades expressivas para seus versos, ampliando o que eles têm de inquietação e recusa em relação às formas codificadas, o poeta também se retrai, quase se retira da cena, transformando-se em agenciador de palavras e sons outros, alheios, muitos dos quais jamais seriam ouvidos (dada a invisibilidade social ou cultural a que estavam submetidos) se assim não fosse. Ética e estética, de novo, vêm aqui se encontrar e problematizar mutuamente.

Poesia pensante, escrita às vezes áspera e inclassificável, os textos que compõem Mais cotidiano que o cotidiano parecem trazer para si, em seu conjunto firme e bem ordenado, algo da beleza dura e frágil de Franz Kafka (sua imagem e seus textos), referência e personagem que aparecem mais de uma vez no livro, e que fornecem o modelo - quem sabe? - desses textos que vislumbram, de um só golpe, a prisão que todos carregamos dentro de nós (Pucheu, 2013, p. 61) e a maneira de nos livrarmos delas. 


\section{Referências}

AGAMBEN, Giorgio (2013). A comunidade que vem. Tradução de Claudio Oliveira. Belo Horizonte: Autêntica.

AGAMBEN, Giorgio (2008). Homo sacer. A vida nua e o poder soberano. Tradução de Henrique Burigo. Belo Horizonte: Editora da UFMG.

DERRIDA, Jacques (2002). Gramatologia. Tradução de Miriam Chnaiderman e Renato Janine Ribeiro. São Paulo: Perspectiva.

FREITAS, Angélica (2012). Um útero é do tamanho de um punho. São Paulo: Cosac Naify.

NANCY, Jean-Luc (2005). Resistência da poesia. Tradução de Silvina Rodrigues Lopes. Lisboa: Vendaval.

PUCHEU, Alberto (2013). Mais cotidiano que o cotidiano Rio de Janeiro: Azougue.

PUCHEU, Alberto (2015a). apoesia contemporânea Rio de Janeiro: Azougue.

PUCHEU, Alberto (2015b). Kafka poeta. Rio de Janeiro: Azougue.

STIGGER, Verônica (2012). Delírio de Damasco Florianópolis: Cultura e Barbárie.

Recebido em abril de 2016.

Aprovado em agosto de 2016.

\section{resumo/abstract/resumen}

\section{Interromper o instante, interrogar o agora: poesia e política em Alberto Pucheu}

Gustavo Silveira Ribeiro

A partir da leitura do mais recente livro de poemas de Alberto Pucheu, busca-se compreender como o autor propõe a construção de um espaço híbrido para a poesia, no qual se entrelaçam, por meio de um questionamento amplo dos sentidos do contemporâneo e de um trabalho de adensamento e amálgama de linguagem, a atividade poética, a reflexão política e a prospecção conceitual.

Palavras-chave: poesia brasileira contemporânea, literatura pensante, Alberto Pucheu. 
Interrupting the instant, questioning the present: poetry and politics in Alberto Pucheu

Gustavo Silveira Ribeiro

Taking as its point of departure Alberto Pucheu's latest volume of poetry, this essay seeks to understand how the author builds a hybrid poetic space. Through a mixed and concentrated linguistic effort, Pucheu's text intertwines poetical activity, political thought and conceptual investigation in order to launch a broad inquiry over the meanings of the contemporary.

Keywords: contemporary Brazilian poetry, literature and thought, Alberto Pucheu.

\section{Interrumpir el instante, interrogar el ahora: poesía y política en Alberto Pucheu}

Gustavo Silveira Ribeiro

A partir de la lectura del más reciente libro del poeta Alberto Pucheu, se busca comprender de qué modo el autor propone la construcción de un espacio híbrido para la poesía, en el cual se mezclan, a través de un cuestionamiento extenso acerca de los sentidos de lo contemporáneo y de un trabajo de condensación y mixtura del lenguaje, la actividad poética, la reflexión política y la prospección conceptual.

Palabras clave: poesía brasileña contemporánea, literatura pensante, Alberto Pucheu. 